What classes have been given assignments that should have had library information included?

What other services are needed?

What are the repeating questions that signal that the reference librarian needs to take action, such as consultation with the professor or changes needed in the catalog format-whether paper or electronic?

Repetitive questions are important for two reasons. First, even the most challenging question ceases to be fun for staff on any level after it is asked for the 25th time in two days. Second, if everyone in the class needs the information, it should be in the course syllabus or library handout.

What reference titles need to be purchased for the questions that weren't being asked three years ago?

What new reference titles or databases need to be developed?

What changes need to be requested from the vendors of CD-ROM databases to make them easier for the public to learn?

What can be done to improve the accuracy of the answers of the reference desk staff?

Are questions being referred unnecessarily to branches or special collections of other libraries?

What training needs to be provided for reference desk staff, both new and experienced?

Maybe the metaphor needed is that a reference librarian's time at the desk should include "preventive medicine."

A busy reference desk is no place for extended interviews for database searching, a lengthy explanation of how to do a literature search, or sensitive questions (i.e., those questions that the public feels are sensitive). It never was. Therefore, reference librarians, in fairness to the public and to colleagues, need to keep "office hours" or to make individual appointments.
An intense concern with reference statistics, measurement, and evaluation has marked the last twenty years. It is well to remember that statistics have to be interpreted. When the reference librarians are doing their best work, the result may, even should be, a drop in the number of transactions at the reference desk because the clients know the answer from signs or handouts or bibliographic instruction, or because the faculty includes the information in the course. And conversely, an increase in reference statistics does not necessarily indicate more or better work.

Technology today offers to librarians opportunities to retry some good ideas from the past for which the technical capability was inadequate; a lessening of time and space constraints on the librarian; opportunities to deal with clients who are too shy, too immobile, or too busy to come to the reference desk; and the possibility of freeing people from dull, repetitive tasks.

What do reference librarians need to be, what do reference librarians need to know to deal with the future? A solid concept of what kind of business reference is and an openness to rethinking reference functions in view of the new technology. Sensitivity to local conditions; in reference services, there are very few programs, ideas, and systems that are effective without careful local modifications. Ability to manage the human aspects and the technical aspects of change. Ability to document the needs and expectations of our clients for the library and university administrations and for designers of new products and systems. The judgment, the ability, and the courage to say "yes" to the new which benefits the library's clientele and "no" to the new which offers only novelty.

What a time to dream things that never were and say "Why not?" What an exciting time to be librarians!

\title{
The future of reference service: Discussion summary
}

\section{By Dennis Dillon}

Reference Librarian

University of Texas at Austin

The ensuing discussion focused primarily on three issues: technology, identifying reference problems, and the pros and cons of the reference desk. The following summary synthesizes audience and panelists' comments on these subjects.

\section{Technology}

Discussion began with several people focusing on the incompatibility, expense, and amount of specialized knowledge needed to operate and maintain the various electronic information systems. This prompted the observation that libraries have never made the best or most innovative use of existing technologies and that we could do more, especially in the area of electronic mail.

One member of the audience responded that we need to look more closely at the high technology of the recent past such as the telephone and the tele- 
phone answering machine, rather than lose our heads over the promise of electronic mail. Telephone technology is already compatible with 200 million users all across the United States. It is interesting that we are willing to spend for some forms of glitzy technology, but not for technology that is more mundane. With the telephone we can instantly contact other libraries and research centers

\section{Specific types of questions}

\section{need special attention, not}

$$
\text { specific user groups. }
$$

around the globe. A telephone brings the world to the reference desk in a way computers cannot. Most libraries can afford to have more telephone lines and answering machines collecting questions than computer terminals. Audience members mentioned that we could also be making better use of facsimile. Electronic mail is not the only electronic communications medium that libraries are underutilizing. But, said one member of the panel, no matter what the technology or what use we are making of it, we need to maintain a balance between the person and the machine. A person will always be needed to monitor what questions are being asked and to decide how best to answer them.

\section{Identifying the problems of reference services}

The discussion then turned to the area of expert systems and libraries' increasing use of computers and electronic databases. Several audience members pointed out that in this era of wondrous electronic tools, we need to remember that tools change both the way people approach and conceptualize problems, and the solutions which people seek or ignore. Just because new tools are available that does not mean that they are appropriate to solving our particular problems.

A systems analyst in the audience again reminded everyone that before setting future directions for reference, we need to have a firm conceptual model of where the problems in reference service are. Only then can we systematically conceive of possible solutions, and develop or search for the tools to correct the problems. He warned that librarians, like everyone else, often approach problems backwards, by looking at the available tools and then trying to force solutions onto them. This not only does not solve the problem, but results in bigger headaches that require even more time and money to solve.

\section{The reference desk and the future of reference}

The issue gathering the most impassioned comments revolved around the question of whether we should continue traditional reference services, or try to arrive at a new paradigm for reference composed of a mixture of reference by appointment, expert systems, a quick information desk staffed by paraprofessionals, and electronic mail. This debate arose because reference librarians are increasingly complaining about being overworked and overstressed; and because there is a sense that the current reference desk does not meet all the needs of its users.

Several participants stated that the quality service was there in the current reference system, but that it just got lost in the volume of services provided, though others admitted that fatigue and other job related factors contributed to less than optimum service.

There was some interest in re-examining the structure of the reference mix based on the context of the question being asked. At present, said one panelist, we level all questions out to a medium level. We do not have the easy questions answered by low-level staff and we do not have the hard questions answered through private consultation with our most highly trained staff. This quickly led to a discussion on the need to divide users into different categories, and carefully consider what we are trying to do with each group. In general the proposal consisted of applying the marketing concept of the targeted audience. For users needing indepth assistance, such as a faculty member working on deadline with grant money, appointments would be logical; while the freshman's question about periodical locations could be answered at a lower level.

One panelist was struck by an earlier audience comment about how people are much more careful and thoughtful when they have to write something down than when they speak. Perhaps, she said, if people did not have a desk to go to, they would think more and become more self-sufficient. They would then be more susceptible to reading library use material and to using expert systems.

There are many other ways to match people and information than the current reference desk. Most librarians don't currently have the skills to make use of existing technology in a creative way. If we take reference librarians off the desk, perhaps they will have the time to be more creative. Or, systems analysts and similar technologically trained people could be hired to design expert systems and other new solutions to the emerging reference problems.

We can be sure of one thing, said one panelist, and that is that the factors affecting reference are constantly changing. We need to insure that we are in a position to lead rather than follow.

Not everyone agreed that doing away with the traditional reference desk was a good idea. Several 
points were raised in its defense.

Some audience members said that one problem with offering tiered reference services such as reference by appointment along with a quick answer desk is that users don't know the context of their own questions. When they preface a reference question by saying I know this is hard, or easy, or short, or long - they are almost always wrong. Not being information professionals, they don't know where their question fits in the information universe any more than a patient going to a physician is aware of the context and ramifications of particular symptoms.

Of course, somebody else besides librarians can answer simple questions, but that is not all that is going on at the reference desk. The reference librarian acts as the library's troubleshooter and front line manager. He or she is right on the information access and transfer scene, and not removed or insulated from user comments and questions. The reference librarian is able to observe the realities of how various library tools and research problems are actually approached and use this information to improve library services.

Several reference librarians mentioned that the question the user asks at the desk is seldom their real question. The librarian using acquired skills and experience can interpret the existence of hidden questions in ways that machines or inexperienced staff members cannot. The existence of the hidden question is communicated non-verbally by gesture, voice inflection, gait, and general demeanor. In this human-to-human interaction the reference librarian through intuition gained by experience analyzes the user and attempts to discern the real question. The librarian then interprets the user's needs in terms of how many sources are needed, at what level of complexity, and how much time the user has to devote to the problem. Unfamiliarity with the universe of information sources or inexperience at analyzing user needs would make the process break down. We need to have high-level people at the reference desk with the knowledge and background to understand the context of the question.

Reference librarians also noted the difference between bibliographic instruction in the classroom and the experience of later helping the same people at the reference desk. The one-on-one interaction at the reference desk is more relevant and earns user respect in ways that prepared material on computers and handouts cannot.

It was also brought up that users seldom grasp subtle differences between service points. The user simply wants to go to the nearest desk and ask for what is needed. It doesn't matter what the desk is called, who is staffing it, or what the user thinks is the context of the question. The user does not want to be put off or referred. We will be judged simply on the service the user gets then and there when the assistance is needed the most.

As for adopting a marketing strategy and target- ing user groups for different levels of service, audience members again reinforced the standard reference librarian's observation that it is difficult to pigeonhole users. If we want to raise the general level of service, it is not the specific user groups that need attention, but specific types of questions. There are legitimate reasons, usually political or educational, for targeting specific user groups for special attention, but doing so does not raise the general level of service; instead, it merely creates special classes of users who receive extra attention and adds yet another service responsibility to the reference librarian's collection of duties.

One panelist mentioned that with the growth of computer searching, users are already becoming used to making appointments with librarians and that perhaps we should expand upon this model. This argument was countered from the audience by a librarian who stated that in her branch library she does all of her scientific and technical searching without appointment. Her users come to the library for information, not to encounter delay, bureaucracy, appointments, or frustration. They get instant service and leave thinking the library is an efficient, quick, and up-to-date operation.

Several reference librarians noted that the type of questions users ask change over time, how they ask for the information changes over time, and how they want that information packaged or delivered changes over time. There is an obvious value in having persons on the firing line at the reference desk who hear how users at all levels are trying to use the library, and knows by what methods they are seeking information this year, so that publications, signs, and electronic systems can be kept relevant. To have information access tools designed and written by people in the absence of first-hand experience and feedback is to court the danger of becoming irrelevant. It is the reference librarian on the reference desk who knows most intimately what users want the library to be.

One panelist noted that people are happy with reference service because they like the personal interaction. She compared the personal interactions of the circulation and the reference desks and noted that users obviously do not have the same positive response to all their circulation transactions that they do with their reference transactions. She said that reference is cushioned from experimenting with alternate methods of information service by its very strength, which is the positive response of its users to the personal interaction at the reference desk. But, added an audience member, one aspect of that positive user response is the immediacy of attention the user gets, and the quick resolution of their questions. Even if the reference librarian tells the user the library cannot help, that at least is an unambiguous quick resolution that allows the user to turn their information pursuit in other directions.

The discussion, of course, ended with no resolution; but the program was invigorating and 


\section{If you want to evaluate your library by}

\section{F. W. Lancaster}

Evaluating library services is less an intellectual exercise than it is a practical activity designed to gather data useful in problem-solving and decision-making within the library. This new book by Lancaster gives you the practical advice you need for evaluating all types of library services.

If You Want to Evaluate Your Library discusses evaluating:

- the collection

- resource sharing

- document delivery and availability

- cost-effectiveness analyses

- materials usage

- cost-benefit studies.

- reference services

A valuable tool for library directors, managers, and administrators, this book will help identify areas of the library that need to be evaluated and the best way to conduct the evaluation. Clear explanations of current issues and modern techniques plus end-of-chapter case-study questions make this book ideal for practicing librarians as well as teachers and students of library science.

Lancaster, Professor of Library and Information Science at the University of Illinois, brings to this new book his twenty years of experience teaching courses on evaluating library services. His earlier book, The Measurement and Evaluation of Library Services, for years has been used as the standard guide to conducting evaluations. That book received the American Library Association's "Ralph Shaw Award" as an outstanding contribution to the literature of library science. Three of his earlier books have received the annual "Best Book" award of the American Society for Information Science.

Order from

\section{The University of Illinois}

\section{Graduate School of Library and Information Science}

Publications Office

249 Armory Building

505 East Armory Street

Champaign IL 61820
208 pages, cloth ISBN: 0-87845-078-5

$\$ 34.50$ plus $\$ 2.50$ postage

Orders must be prepaid to the University of Illinois. 


\title{
The Tax Reform Act of $\mathbf{1 9 8 4}$
}

\section{and American research libraries}

\author{
By the Ad Hoc RBMS Legislative Information Committee \\ Timothy Murray, compiler \\ University of Delaware
}

\section{Have the new regulations had an impact?}

\begin{abstract}
$\mathbf{T}$ he Tax Reform Act of 1984 placed potential new burdens on donors and libraries in the administration of noncash gifts. Since January 1, 1985, the Internal Revenue Service requires donors to maintain detailed records concerning all gifts of property, other than cash and publicly traded securities, with a value greater than $\$ 500$ for which they claim a tax deduction. In addition, the regulations mandate specific institutional reporting procedures for gifts of property with values greater than $\$ 5,000$. Donors must also total the value of smaller gifts of similar property to more than one institution and if the aggregate is greater than $\$ 5,000$, the new reporting rules, for donor and donee, will apply. Finally, the regulations have placed the appraisal process under greater scrutiny. ${ }^{1}$
\end{abstract}

'The text of the law can be found in Deficit Reduction Act of 1984. Division A: Tax Reform Act of 1984. House of Representatives Report \#98-861, 98th Congress, 2nd Session (1984), pp. 206-11. Temporary implementation rules and regulations appear in Federal Register 49, no.252 (December $31,1984)$. In 1988 , the temporary status of the new regulations was removed and the final implementation rules and regulations are printed in Federal Register 53, no.87 (May 5. 1988).

The relevant forms used for the new reporting procedures are Forms 8283 and 8282 . Form 8283 ,
Following the Tax Reform Act of 1969, which eliminated tax deductions based on the donation of cultural and historical documents to non-profit institutions by their creators, research libraries reported significant declines in such donations directly resulting from new regulations mandated in that act. ${ }^{2}$ Since the 1984 regulations also defined and mandated a series of new documentation and

Section B is the appraisal summary which is completed by the donee and a qualified appraiser for gifts of property with an appraised value in excess of $\$ 5,000$. Form 8282 must be completed by a donee to report the disposal of any donated property, for which a form 8283 was completed, within two years of its original receipt. Under the initial regulations, the donee was required to complete Form 8282 for all such disposals. The final regulations have modified this requirement and the revised instructions for Form 8283 include the following note: "an exception applies to items having a value of $\$ 500$ or less which are part of a group of similar items contributed. For these items a donee organization does not have to file Form 8282 if the donor completed and signed the statement in Part II (Section B) of Form 8283."

${ }^{2}$ Norman E. Tanis and Cindy Ventuleth report the continuing effects of the 1969 legislation in "The Decline in Donations? Effects of the Tax Reform Act of 1969," Library Journal 111, no.11 (June 15, 1986): 41-44. 